\title{
A desobediência epistêmica e as mulheres como sujeitos historiográficos
}

\author{
La desobediencia epistémica y las mujeres como sujetos de la historiografía
}

\section{Stella Ferreira Gontijo"}

Resumo: Este artigo tem como objetivo propor uma reflexão inicial acerca da relação entre a desobediência epistêmica e os estudos que consideram o gênero como uma categoria de análise histórica e outros diversos sujeitos excluídos da narrativa da História. Para isto, partimos de um percurso teórico que começa com a História das Mulheres, tem como fundamental os Estudos de Gênero, e atualmente termina na Teoria Descolonial. Como o feminismo descolonial contribui para romper com uma epistemologia colonial? O que a forma do conhecimento tem a ver com a reprodução das relações de poder? Para essas reflexões consideramos autoras e autores fundamentais como Aníbal Quijano, Walter Mignolo, María Lugones e Rita Segato.

Palavras-chave: Teoria descolonial; Feminismo Latino-Americano; Estudos de Gênero.

Resumen: Este artículo tiene como objetivo reflexionar inicialmente acerca de la relación entre la desobediencia epistémica y los estudios que consideran el género como una categoría de análisis histórico y otros diversos sujetos excluidos de la narrativa de la historia. Para ello, partimos de un recorrido teórico que comienza con la Historia de las Mujeres, tiene como fundamental los Estudios de Género, y actualmente termina en la Teoría Descolonial. ¿Cómo contribuye el feminismo descolonial a romper con una epistemología colonial? ¿Lo que la forma del conocimiento tiene que ver con la reproducción de las relaciones de poder? Para esas reflexiones consideramos autoras y autores fundamentales como Aníbal Quijano, Walter Mignolo, María Lugones y Rita Segato.

\footnotetext{
"Mestre em História pela Universidade Federal Fluminense, com dissertação intitulada "Hasta que seamos libres: feminismo e Revolução Sandinista nas obras de Gioconda Belli (1972 - 1993), defendida em 2019 sob orientação da Profa. Dra. Elisa de Campos Borges. Graduada em História pela Universidade Federal de Minas Gerais. Membro do Núcleo de Pesquisa em História das Américas - NUPHA UFMG. E-mail para contato: sfgontijo@gmail.com
} 
Palabras clave: Teoría descolonia; Feminismo Latinoamericano; Estudios de Género.

Na dissertação de mestrado, ao pensarmos o feminismo e a Revolução Sandinista a partir da análise da obra da nicaraguense Gioconda Belli, nos deparamos com diversos desafios que passavam pelo fato de estudarmos não só as mulheres latino-americanas, mas também uma intelectual mulher. Este artigo tem então como objetivo dar continuidade a um debate iniciado de maneira tímida anteriormente, sobre reflexões acerca das abordagens do feminismo latino-americano; sobre como teórico e metodologicamente lidamos para a inclusão das mulheres na história, quais as especificidades de se estudar a América Latina não apenas da categoria de gênero e da inclusão das mulheres na historiografia. Sobre os desafios e especificidades de se estudar as mulheres da América Latina, a partir de uma perspectiva teórica latino-americana e questões que partem da realidade latino-americana, entendemos que, para pensar a América Latina, devemos ter como central pensadoras e pensadores que falam deste lugar, que buscam romper com um pensamento científico eurocêntrico, branco, Ocidental e cristão. Estes pontos se intensificam quando vamos pensar na escrita da história, a partir dos Estudos de Gênero e da História Intelectual/dos Intelectuais, em busca da inclusão da narrativa das mulheres, entendendo-as como sujeitas e atrizes da História.

O uso da categoria gênero para análise histórica tem sido colocado, principalmente, desde o famoso artigo publicado pela norte-americana Joan Scott ${ }^{\mathrm{I}} \mathrm{em}$ meados da década de 1980. É importante ressaltar que o uso da categoria mulher já vinha sendo utilizado desde a ascensão da História das Mulheres - lembrando das diferenças substanciais entre essa perspectiva e os Estudos de Gênero, que surgem posteriormente. Já no início do século XX, a Escola dos Annales surge em contraposição à visão positivista da história, propondo novas abordagens, sujeitos e fontes para a pesquisa historiográfica e, nesse primeiro momento, vêse uma tímida inclusão das mulheres na historiografia produzida, que buscava romper com uma visão de verdade absoluta da História. Com essa nova proposta, na década de I980, a Terceira Geração dos Annales vai provocar o que Réne Rémond (2003) chama de "renovação da história política”. E, a partir do contato interdisciplinar com a antropologia e a sociologia,

I Joan Wallach Scott é uma pesquisadora estadunidense, professora na School of Social Science, Institute for Advanced Study Princeton, Nova Jersey. Autora do artigo Gender: a useful category of historical analyses, originalmente publicado na American Historical Review, em I986, posteriormente integrando seu livro Gender and the Politics of History, de I989. Foi traduzido para o português e publicado em 1995, na revista Educação E Realidade, Porto Alegre, v. 20, n. 2, jul./dez. Esse artigo é considerado precursor dos Estudos de Gênero. 
vai entender o político também a partir da dimensão dos fatos coletivos, como lugar de articulação do todo social.

Com a ampliação das fronteiras do político e o surgimento de novos sujeitos da História emerge a História das Mulheres, que buscava inserir a perspectiva e a participação das mulheres nos processos diversos. É importante ressaltar a relevância das contribuições de Michelle Perrot (1995) que, acompanhada de outras historiadoras ${ }^{2}$, foi precursora na inclusão das mulheres na história, como objeto de estudo e como personagens a serem consideradas: "os historiadores anteriores dos Annales haviam sido criticados pelas feministas por deixarem a mulher fora da história, ou mais exatamente, por terem perdido a oportunidade de incorporá-la à história de maneira mais integral" (BURKE, I99I, p.56).

A História das Mulheres proposta por Michele Perrot compreende que escrever a História das Mulheres está relacionado à visão de que elas são agentes históricos, que possuem uma historicidade, também manifestada nas relações de sexo-gênero, questões que só foram consideradas pela historiografia quando esta "se mostrará mais receptiva quanto à presença da dimensão sexuada no interior da evolução histórico-temporal" (PERROT, 1995, p.I5). Nesse momento em que uma maior atenção foi dada à vida privada, as mulheres surgem como um campo a ser explorado, o que não significava, necessariamente, o seu entendimento enquanto protagonistas da História e sujeitos sociais significativos:

Tratava-se inicialmente de tornar visível o que estava escondido, de reencontrar traços e de se questionar sobre as razões do silêncio que envolvia as mulheres enquanto sujeitos da história. Isso conduziu a uma reflexão em torno da história enquanto produto da dominação masculina, a qual atuava em dois níveis: nível dos próprios acontecimentos e nível da elaboração deles empreendida pelo relato. [...] Mais adiante, nos questionamos sobre as mulheres enquanto agentes responsáveis pelos seus destinos individuais e coletivos, sobre suas capacidades de resistência e de transformação. Procuramos compreender o papel das mulheres nos movimentos sociais e nas revoluções. Fez-se a história do feminismo. (PERROT, 1995, p. 20-2I)

Apesar da importância acadêmica do surgimento dessa abordagem, a História das Mulheres não visava, num primeiro momento, o rompimento epistemológico com a

2 Christiane Klapisch, Arlette Farge, Mona Ozouf. 
historiografia feita até então, mas sim buscava incluir as mulheres na narrativa já consolidada. A importância da emergência da História das Mulheres também se destaca por desafiar a autoridade dominante na Academia, adotando uma narrativa política ao emergir junto com o movimento feminista e com a campanha por melhorias profissionais e expansão dos limites da história. Ao reivindicarem a inclusão das mulheres como sujeito vão na contramão da historiografia e de seus agentes estabelecidos como "verdadeiros", enfrentando os padrões hegemônicos e corroborando para a formação de um discurso de identidade coletiva.

Com a ascensão dos Estudos de Gênero, em fins da década de 1980, temos a fragmentação da ideia universal de mulher, ampliando a percepção da História das Mulheres e buscando cuidar dos "relacionamentos macho/fêmea e de questões sobre como o gênero é percebido, que processos são esses que estabelecem as instituições geradas, e das diferenças que a raça, a classe, a etnia e a sexualidade produziram na experiência histórica das mulheres." (SCOTT, 1992, p. 88). Para Louise A. Tilly (1994), o aspecto relacional do gênero - ou seja, que o feminino e o masculino existem em relação um com o outro - e a ideia reafirmada por Maria Izilda Matos (2009) de que o social é historicamente construído, o reforça como uma categoria conceitual que exprime "um engajamento político no sentido de promover a igualdade dos gêneros e o acesso das mulheres tanto à autonomia individual quanto ao poder político e econômico" (TILLY, 1994, p. 44).

A precursora do gênero como categoria para análise histórica, Joan Scott (1995 [1986]), vai dar início a um debate sobre a produção de uma ciência feminista, de novos sujeitos e novos campos de análise. Scott (I995, p. 04) propõe uma forma de abordagem histórica, que parte do entendimento de que as categorias de sexo e gênero são relacionais e, com isso, inscrever as mulheres na história "implica necessariamente a redefinição e o alargamento das noções tradicionais do que é historicamente importante, para incluir tanto a experiência pessoal e subjetiva quanto as atividades públicas e políticas.” A partir dessas noções, ela desenvolve o gênero como uma categoria de análise, a partir da qual:

[...] é evidente que escolhemos problemas concretos para estudar e esses problemas constituem começos ou tomadas sobre processos complexos, mas são processos que temos que ter sempre presentes em mente. [...] Para fazer surgir o sentido temos que tratar o sujeito individual tanto quanto da organização social e articular a natureza das suas interrelações, pois ambos 
têm uma importância crucial para compreender como funciona o gênero e como se dá a mudança. (SCOTT, 1995, p. 20)

Para isso, a autora compreende o gênero não apenas como um conjunto de relações sociais, de estereótipos construídos socialmente e que se baseiam nas diferenças de sexo, mas também como uma forma primeira de significar as relações de poder. Ao construir relações sociais, símbolos culturais, representações, conceitos normativos e ao adotar uma concepção binária entre o masculino e o feminino, "a história é construída como se essas posições normativas fosses o produto de um consenso social e não de um conflito." (SCOTT, 1995, p. 2I). Essa nova forma de se escrever a história questiona, justamente, essa representação binária dos gêneros, que se constitui nas estruturas hierárquicas da sociedade, concebida como uma forma de dominação e de controle sobre as mulheres. Ao questionar esse poder estabelecido a partir do gênero,

[...] os historiadores procuram encontrar as maneiras como o conceito de gênero legitima e constrói as relações sociais, eles/elas começam a compreender a natureza recíproca do gênero e da sociedade e das formas particulares, situadas em contextos específicos, como a política constrói o gênero e como o gênero constrói a política. (SCOTT, 1995, p. 23)

Apesar da importância metodológica deste debate, para se pensar a América Latina devemos ir mais além. No Brasil, Margareth Rago vai publicar em 1988 o artigo: Epistemologia feminista, gênero e história, em que pensa na construção de novos conhecimentos e nova forma de produzir o conhecimento na contramão da história totalizante e vista como verdade, considerando esta como marcadamente masculina. Para a autora, para inscrever a perspectiva das mulheres e compreendendo as mulheres como sujeitos e atrizes da história, seria fundamental o rompimento com essa visão epistemológica hegemônica. Segundo ela é necessário, inclusive, uma nova linguagem para produção de um contradiscurso. Essa crítica feminista denuncia o caráter particularista, racista, sexista e ideológico que opera no conhecimento científico Ocidental, incapaz de refletir a partir das diferenças.

A historiografia acerca da América Latina e, com nosso foco nos processos revolucionários do século XX, não destoa dessa narrativa hegemônica construída que exclui as mulheres. O comum era - e apesar dos avanços que vem sendo feitos, ainda é - a presença de um sujeito universal reconhecido como masculino, representado pela categoria homem, como afirmam Rachel Soihet e Joana Maria Pedro (2007, p. 284): 
Acreditava-se que, ao falar dos homens, as mulheres estariam sendo, igualmente, contempladas, o que não correspondia à realidade. Mas, também, não eram todos os homens que estavam representados nesse termo: via de regra, era o homem branco ocidental.

Para rompermos com essa construção narrativa e teórica da concepção de sujeito da história e para pensar a realidade latino-americana devemos, não apenas incluir a categoria mulher, mas mulheres, entendidas a partir da multiplicidade das mulheres latino-americanas, que não devem ser compreendidas a partir de uma visão eurocêntrica e/ou norte-americana, por não darem conta da complexidade e da diversidade dessas mulheres e de suas realidades - uma vez dissimiles, não podem ser vistas a partir de uma perspectiva totalizante. Precisamos ter também com centralidade as relações de classe, raça, etnia e sexualidade, marcadores fundamentais da realidade latino-americana. Para Breno Cypriano (2013, p. I4):

[...] deve-se resgatar a inspiração de Gloria Anzaldúa para o feminismo do Sul, o feminismo latinoamericano, na sua condição de dubiedade, de suas inconsequências, buscas, desconstruções e questionamentos ao mainstream do Norte global, ao malestream da teoria vigente, americanismo, branqueamento, ocidentalismo e imperialismo dos feminismos norteamericano e europeu, que revolucionou na década de 80 os estudos feministas e de gênero, tanto na literatura, como na concepção estruturalista/fronteiriça (na geografia territorial e a dos corpos).

É nesse sentido que consideramos a Teoria Descolonial como uma perspectiva de análise útil para a compreensão da América Latina e do feminismo latino-americano. $\mathrm{O}$ debate dos feminismos é amplo e deve ser analisado de maneira cuidadosa; principalmente, quando consideramos a pluralidade das culturas, da história e das trajetórias dos diversos países da região. Se não encontramos uma visão hegemônica e homogênea de um debate que já era mais amplo, profundo e antigo, sobre o que seria a Revolução latino-americana, muito menos isso ocorrerá em se tratando do atual debate de gênero.

Partimos do entendimento de que os debates políticos e intelectuais que se davam no mundo ocidental encontravam ressonância na América Latina, e não pretendemos aqui rechaçar toda e qualquer teoria advinda do Norte global. Pelo contrário, concordamos com José Elias Paltí (2007) que devemos buscar compreender a América Latina a partir de seus 
próprios termos e conceitos, ou pela forma como os conceitos foram reincorporados à realidade latino-americana. Portanto, é necessário romper com o Eurocentrismo e refletir acerca da história e do pensamento latino-americano como algo próprio.

Essa posição epistemológica não é algo exclusivo da Teoria Descolonial, mas desde o início do século XX já temos nomes como o intelectual peruano José Carlos Mariátegui (I979 [1925]) que defendia, já em 1920, a possibilidade de um pensamento latino-americano autêntico. Também no mesmo período José Vasconcelos (1978 [1927]) afirma que a filosofia latino-americana surge de sua própria realidade, e que a necessidade de emancipação do pensamento é fundamental para a autonomia política. Para Breno Cypriano (2013, p. 33), devese pensar um "tráfego" e "tráfico" entre as teorias e os subalternos, que desconstrói os discursos hegemônicos. Para isso, é necessário que problematizemos os modelos de conhecimentos, propondo novas abordagens, "redescobrindo e problematizando a partir de nossa América Latina”. Para ele (2013, p. 20),

[...] pensar do ponto de vista e da perspectiva da América Latina em um projeto teórico político feminista e de gênero conforma-se com a necessidade de se formatar uma outra "teoria política feminista" (que ainda permanece entre aspas), visto que a experiência vivida pelo movimento feminista latino-americano reflete-se em um processo complexo de interseções que se deu a partir de um conjunto diferenciado de opressões, pois combina o colonialismo francês, espanhol e português, com os governos ditatoriais e populistas, com dinâmicas específicas da globalização econômica, cultural e política.

A partir dessas considerações, entendemos que não há maneira melhor para pensarmos a América Latina e o feminismo latino-americano, senão com base em uma epistemologia decolonial. Segundo Aníbal Quijano (2000, p. 246-276), o conhecimento, até então produzido com a modernidade, demonstra a relação de poder do moderno/capitalista/eurocentrado sobre o colonial. Assim, o conhecimento está sujeito às relações de poder estabelecidas com a colonização, que nega o conhecimento produzido fora do norte global. Para Luciana Ballestrini (20I3, p. I09), "decolonizar a teoria, em especial a teoria política, é um dos passos para decolonização do próprio poder". Ou seja, a construção de um conhecimento científico próprio, que advém de uma intelectualidade latino- 
americana - sem desconsiderar o produzido e incorporado do Norte global - é parte fundamental para a luta de emancipação.

\section{A epistemologia descolonial}

O grupo Modernidade/Colonialidade surge em 1998 a partir de divergências com o grupo de Estudos Subalternos, formado, principalmente, por indianos como Ranajit Guha, Gayatri Spivak, Homi Bhabha, que existia desde a década de 1980. Esse novo grupo, formado fundamentalmente por latino-americanos, surge com Aníbal Quijano e Walter Mignolo como alguns de seus principais teóricos. Segundo Ballestrini (2013, p. 95-96):

Mignolo denuncia o "imperialismo" dos estudos culturais, pós-coloniais e subalternos que não realizaram uma ruptura adequada com autores eurocêntricos (Mignolo, 1998). Para ele, o grupo dos latinos subalternos não deveria se espelhar na resposta indiana ao colonialismo, já que a trajetória da América Latina de dominação e resistência estava ela própria oculta no debate. A história do continente para o desenvolvimento do capitalismo mundial fora diferenciada, sendo a primeira a sofrer a violência do esquema colonial/imperial moderno. Além disso, os latino-americanos migrantes possuem outras relações de colonialidade por parte do novo império estadunidense - ele mesmo tendo sido uma colônia nas Américas.

O conceito desenvolvido por Aníbal Quijano de colonialidade do poder vai ser um dos principais norteadores desses/as pesquisadores/as, que vão pensar as permanências da relação de poder colonial, mesmo após o fim do período denominado pela história global como da colonização. Assim, a "colonialidade se reproduz em uma tripla dimensão: a do poder, do saber e do ser. E mais do que isso: a colonialidade é o lado obscuro e necessário da modernidade; é a sua parte indissociavelmente constitutiva." (QUIJANO, 2000, p. IOO).

Nesse sentido, a colonialidade do saber, que dá origem a uma geopolítica do conhecimento, é fundamental para manutenção da lógica colonial-moderna do poder, partindo de uma perspectiva eurocêntrica do conhecimento, consolidado a partir do colonialismo europeu em outras partes do globo, que naturaliza as relações de dominação a partir da raça e que, segundo Quijano (2000, p. II8), historicamente significou "uma nova maneira de legitimar as já antigas idéias e práticas de relações de superioridade/inferioridade entre dominantes e dominados.” Para ele (2005, p. 09): “A elaboração intelectual do processo 
de modernidade produziu uma perspectiva de conhecimento e um modo de produzir conhecimento que demonstram o caráter do padrão mundial de poder: colonial/moderno, capitalista e eurocentrado." Ou seja, o padrão eurocêntrico do conhecimento vai, a partir da narrativa e de uma ideia de ciência, normatizar uma relação de poder desigual e opressora na História, re-situando temporalmente outros povos e culturas como pré-históricos,

Não seria possível explicar de outro modo, satisfatoriamente em todo caso, a elaboração do eurocentrismo como perspectiva hegemônica de conhecimento, da versão eurocêntrica da modernidade e seus dois principais mitos fundacionais: um, a idéia-imagem da história da civilização humana como uma trajetória que parte de um estado de natureza e culmina na Europa. E dois, outorgar sentido às diferenças entre Europa e não-Europa como diferenças de natureza (racial) e não de história do poder. Ambos os mitos podem ser reconhecidos, inequivocamente, no fundamento do evolucionismo e do dualismo, dois dos elementos nucleares do eurocentrismo. (QUIJANO, 2005, p. I22)

Essa diferença colonial epistêmica, nas relações do saber, é constituída e constituinte do racismo e do sexismo, a partir da ideia do universal, que nada mais é que o sujeito homem, branco, Ocidental, cristão, burguês. Ou seja, é o que afirma Mignolo (2008B) sobre a geopolítica do conhecimento ser uma forma de controle da hegemonia de um conhecimento racista e patriarcal. Em confronto com o conhecimento hegemônico instituído, o então chamado "Giro Descolonial" - termo criado por Nelson Maldonado-Torres 3 - significa, segundo Ballestrini (2013, p. I05), "o movimento de resistência teórico e prático, político e epistemológico, à lógica da modernidade/colonialidade.” Para Mignolo (2008B, p. 242) esse pensamento descolonial é caracterizado pelo "desprendimento do eurocentrismo como esfera do conhecimento, a partir do qual é possível controlar a economia, a autoridade, o gênero e a sexualidade, em suma, a subjetividade."

Walter Mignolo vai localizar esse pensamento como "fronteiriço" - conceito que fora apropriado por Breno Cypriano. Segundo Mignolo, a partir deste este é

3 MALDONADO-TORRES, Nelson. Analítica da colonialidade e da decolonialidade: algumas dimensões básicas. In: BERNARDINO-COSTA, Joaze; MALDONADOTORRES, Nelson e GRASFOGUEL, Ramón (orgs.) Decolonialidade e pensamento afrodiaspórico. Belo Horizonte: Autêntica Editora, 2018, pp. 27-53. 
é assumido que não há o "fora", mas que o pensamento surge da exterioridade (a criação do fora pelo dentro), isto é, na fronteira. Mas uma fronteira na qual os dois lados não estão em igualdade de condições. Daí a diferença epistêmica e ontológica colonial a partir da qual reclamam seus direitos epistêmicos (e não seu privilégio) aqueles que foram deixados de fora do jogo e das decisões. [...] opção descolonial, e por isso é uma opção e paradigma de coexistência, rejeita sempre uma única maneira de ler a realidade, seja esta cristã, liberal ou marxista. Esses pensamentos totalizantes, criadores de totalidade, estão em conflito com o pensamento fronteiriço e a opção descolonial." (MIGNOLO, 200B, p. 246)

Decolonizar a teoria é um passo para decolonização do poder e de descolonizar a História. Assim, a partir da Teoria Descolonial e do debate sobre a produção de novas formas de conhecimento, que considere novos sujeitos e novas fontes, vamos refletir sobre como, a partir daí, inserirmos as mulheres na historiografia.

\section{O feminismo descolonial como desobediência epistêmica}

O feminismo descolonial é um conceito que tem como principal referência teórica a argentina Maria Lugones, desenvolvido a partir de críticas da exclusão da categoria de gênero da Teoria do Descolonial, desenvolvido por Quijano. Para ela, a violência colonial, resultado da colonialidade do poder, não pode ser separado da colonialidade do gênero. A partir daí vai desenvolver eixos importantes como: críticas do feminismo hegemônico que nega a interseccionalidade de gênero/raça/classe/sexualidade, e que parte da ideia de que existe uma mulher universal, sendo esta branca e Ocidental; reflexões sobre como o homem colonizado também reproduz a violência de gênero do patriarcado, cúmplices e colaboradores da violência exercida sob as mulheres de cor. Nesse sentido, segundo Lugones (2008, p. 78):

para Quijano, las luchas por el control del «acceso sexual, sus recursos y productos» definen el ámbito del sexo/género y, están organizadas por los ejes de la colonialidad y de la modernidad. Este análisis de la construcción moderna/colonial del género y su alcance es limitado. La mirada de Quijano presupone una compresión patriarcal y heterosexual de las disputas por el control del sexo y sus recursos y productos. Quijano acepta el entendimiento 
capitalista, eurocentrado y global de género. El marco de análisis, en tanto capitalista, eurocentrado y global, vela las maneras en que las mujeres colonizadas, no-blancas, fueron subordinadas y desprovistas de poder. El carácter heterosexual y patriarcal de las relaciones sociales puede ser percibido como opresivo al desenmascarar las presuposiciones de este marco analítico. [...] Entender los rasgos históricamente específicos de la organización del género en el sistema moderno/colonial de género (dimorfismo biológico, la organización patriarcal y heterosexual de las relaciones sociales) es central a una comprensión de la organización diferencial del género en términos raciales.

A construção da heterossexualidade, do binarismo relacional homem/mulher, são frutos da modernidade colonial, que se organiza dessa forma a partir da ascensão do capitalismo e do patriarcado. Assim, as mulheres latino-americana não se encontram numa situação de submissão colonial somente racial, mas também por serem mulheres e, mais ainda, mulheres de cor, dessa forma, "Solo al percibir género y raza como entretramados o fusionados indisolublemente, podemos realmente ver a las mujeres de color." (LUGONES, 2008, p. 82).

A opressão exercida sobre as mulheres de cor, que deixam de ser entendidas como sujeitos e são desumanizadas, é um processo do Estado patriarcal imposto pela colonização, sendo que, as relações de gênero patriarcais da forma como conhecemos, vão ser inseridas onde anteriormente não existia essa hierarquia estabelecida entre homens e mulheres. Esse processo se dá, por exemplo, com a redução da pluralidade espiritual das tribos, que em sua grande maioria tinham as mulheres no centro, com a imposição do deus cristão/ homem. Ou, com a centralidade da imposição da família nuclear burguesa que retira a mulher de espaços de poder e entendidos como da política e do político, relegando-as ao espaço da família e do privado, compreendendo este como da esfera individual e retirando das mulheres qualquer tipo de autonomia e de capacidade de incidir na dinâmica coletiva. Dessa forma,

Concebir el alcance del sistema de género del capitalismo eurocentrado global, es entender hasta qué punto el proceso de reducción del concepto de género al control del sexo, sus recursos, y productos es constitutiva de la dominación de género. [...] La reducción del género a lo privado, al control sobre el sexo y sus recursos y productos es una cuestión ideológica 
presentada ideológicamente como biológica, parte de la producción cognitiva de la modernidad que ha conceptualizado la raza como «engenerizada» y al género como racializado de maneras particularmente diferenciadas entre los europeos-as/blancos-as y las gentes colonizadas/noblancas. La raza no es ni más mítica ni más ficticia que el género -ambos son ficciones poderosas. (LUGONES, 2008, p. 93-94)

Ao desumanizar as mulheres do Sul global, fica claro como a construção do conceito universal de mulher é criado a partir da única mulher existente na modernidade colonial, aquela responsável pela reprodução da classe burguesa: a mulher branca, Ocidental, cristã. À medida que desenvolve sua teoria, Lugones vai propor o sistema moderno colonial de gênero, que nada mais é do que "uma lente através da qual aprofundar a teorização da lógica opressiva da modernidade colonial, seu uso de dicotomias hierárquicas e de lógica categorial. Quero enfatizar que a lógica categorial dicotômica e hierárquica é central para o pensamento capitalista e colonial moderno sobre raça, gênero e sexualidade.” (LUGONES, 20I4, p. 935). Esta é uma opressão de gênero racializada e capitalista que recai sobre as mulheres de cor do Sul global e, para superar a colonialidade de gênero é fundamental que partamos de um feminismo descolonial, que desponta como uma forma de resistência à colonialidade de gênero a partir de diferença colonial:

A colonialidade do gênero permite-me compreender a opressão como uma interação complexa de sistemas econômicos, racializantes e engendrados, na qual cada pessoa no encontro colonial pode ser vista como um ser vivo, histórico, plenamente caracterizado. Como tal, quero compreender aquele/a que resiste como oprimido/a pela construção colonizadora do lócus fraturado. (LUGONES, 20I4, p. 940-94I)

Para tratar esse tema do feminismo descolonial e de um rompimento epistemológico com a historiografia hegemônica, que vem ocorrendo desde a década de 1980 com afãs de partir de uma perspectiva que considere as mulheres como sujeitas e atrizes da História, recorremos à metodologia proposta por Mignolo (2008A) da desobediência epistêmica. Ele parte do princípio, que já apontamos aqui anteriormente, da forma como a razão é instrumentalizada pelo poder colonial (colonialidade do saber), a partir de uma falsa impressão de totalidade, que nada mais é que eurocêntrica, Ocidental, heterossexual, 
masculinizada, branca e cristã. Assim, a ação de romper com essa perspectiva universal e totalizante é a desobediência epistêmica. Segundo este autor (2008A, p. 290; 297),

\begin{abstract}
A opção descolonial é epistêmica, ou seja, ela se desvincula dos fundamentos genuínos dos conceitos ocidentais e da acumulação de conhecimento. Por desvinculamento epistêmico não quero dizer abandono ou ignorância do que já foi institucionalizado por todo o planeta. [...] a opção descolonial revela a identidade escondida sob a pretensão de teorias democráticas universais ao mesmo tempo que constrói identidades racializadas que foram erigidas pela hegemonia das categorias de pensamento, histórias e experiências do ocidente.
\end{abstract}

A saída apontada por ele como pensamento de fronteira - que tratamos brevemente anteriormente - tem como objetivo não radicalizar nem na exclusão de todo e qualquer conhecimento produzido no Norte global, nem com a aceitação apenas do que é produzido no Sul global. Assim, visa confrontar as categorias de pensamento do Ocidente a medida em que novas abordagens e análises são desenvolvidas no Sul. Nesse sentido o eurocentrismo é entendido não como um lugar geográfico, mas como uma forma de pensamento hegemônico que deve ser encarado e enfrentar resistências subalternas. Para isso, a teoria descolonial apresenta a multiplicidade, a pluriversalidade, como o feminismo descolonial faz ao romper com a ideia universal da mulher, para partir de uma concepção que tem como premissa a existência de diversas de mulheres, mais fundamentalmente mulheres (latino-americanas) de cor. Dessa maneira, a partir de uma posição epistêmica subalterna se constrói outro pensamento: "Descolonial implica pensar a partir das línguas e das categorias de pensamento não incluídas nos fundamentos dos pensamentos ocidentais." (MIGNOLO, 2008A, p. 304-305). A opção descolonial demanda ser epistêmicamente desobediente.

A perspectiva descolonial então surge para nós como uma prática acadêmica (SEGATO, 20I2) que visa romper, na historiografia, tanto com a perspectiva totalizante quando com a de verdade histórica. Assim, não só os sujeitos são múltiplos, mas a História também se assume como uma categoria plural:

Os sujeitos coletivos dessa pluralidade de histórias são os povos, com autonomia deliberativa para realizar seu processo histórico, ainda que em contato, como sempre foi, com a experiência, as soluções e os processos de 
outros povos. Sob esta perspectiva, cada povo é percebido não a partir da diferença de um patrimônio substantivo, estável, permanente e fixo de cultura, ou uma episteme cristalizada, mas sim como um vetor histórico." (SEGATO, 20I2, p. III)

Para Raewyn Connell (20I6), existe uma prática epistêmica nas ciências humanas em que o Sul global exporta os dados e importa a teoria desenvolvida no Norte global. No caso dos estudos de gênero, essa autora apontará uma crítica à hegemonia de autoras e autores como Simone de Beauvoir, Judith Butler e Michel Foucault, para se pensar o gênero como categoria de análise na América Latina. Isso significa que "as experiências sociais e práticas de uma minoria privilegiada da população mundial se tornaram a base da teoria, da metodologia e de generalizações que dominam a produção do conhecimento no restante do mundo.” (CONNELL, 20I6, p. I8). As análises de gênero em sua grande maioria estão inseridas na "economia política global do conhecimento" ${ }^{4}$ e, para romper com essa perspectiva faz-se necessário que tenhamos as teóricas e teóricos do Sul, descolonizando o método científico das humanidades.

\section{Conclusões}

A partir das reflexões apresentadas, neste artigo, concluímos a necessidade de pensarmos a América Latina e, em nosso caso, fundamentalmente as mulheres e os feminismos latino-americano, a partir de concepções teóricas que partam da realidade do Sul global, rompendo com uma perspectiva totalizante do conhecimento científico que busca normatizar a narrativa da História. A partir desse movimento teórico-metodológico, durante séculos inferiorizou-se as culturas e os processos do Sul global como pré-históricos, o que demonstra a relação fundamental entre a colonialidade do saber e do poder. Segundo Mignolo (2008B, p. 244), "O privilégio epistêmico da modernidade é o que gera e mantém a colonialidade do saber e do ser."

Pensar as mulheres como sujeito já rompe com uma epistemologia largamente difundida como universal. Pensar a História do feminismo e este como uma teoria política, partindo da consideração de mulheres como intelectuais e do gênero como categoria de

\footnotetext{
4 "Diferentes autores/as sustentam a existência de uma divisão global do trabalho que reproduz a lógica da geopolítica colonial e neoliberal: é do Norte global onde a criação de teorias com pretensões universais e explicativas são exportadas, estimulando um complexo processo de dependência acadêmica." (BALLESTRINI, 20I7, p. 1035)
} 
análise histórica, nos coloca diversos desafios e em uma posição de enfrentamento dentro da Academia. Mas, como afirma Lugones (2014, p. 95I), "Estamos nos movendo em um tempo de encruzilhadas, de vermos umas às outras na diferença colonial construindo uma nova sujeita de uma nova geopolítica feminista de saber e amar."

Dessa forma, consideramos que a Teoria Descolonial abre novas perspectivas de análises que podem corroborar com pesquisas acadêmicas nas ciências humanas produzidas no Brasil, que buscam inserir novas trizes e novos atores na historiografia, reescrevendo a História, e que estão em busca de uma maior compreensão da formação política, social e cultural do Sul global, fora das normas impostas pela modernidade eurocêntrica do conhecimento.

\section{REFERÊNCIAS BIBLIOGRÁFICAS}

BALLESTRINI, Luciana. “América Latina e o giro decolonial”. In.: Revista Brasileira de Ciência Política, Brasília. n. II, p. 89-II7, mai./ago. 2013;

. "Feminismos subalternos". In.: Estudos Feministas. Florianópolis, 25(3), set.-dez. 2017, p.I034-I054;

BURKE, Peter. “A Terceira Geração”. In: A Revolução Francesa da historiografia: a Escola dos Annales 1929-1989. São Paulo: Editora Universidade Estadual Paulista, I99I;

CONNELL, Raewyn. Gênero em termos reais. São Paulo: nVersos, 20ı6;

CYPRIANO, Breno. "Construções do pensamento feminista latino-americano". In.: Revista Estudos Feminista. Florianópolis, v. 2I, n. I, p. II-40, jan./abr. 20I3;

LUGONES, María. “Colonialidad y género”. In.: Revista Tabula Rasa. Bogotá, n. 9, p. 73-IoI, jul./dez. 2008;

. "Rumo a um feminismo descolonial". In.: Estudos feministas.Florianópolis, 22(3): 320, set.-dez. 20I4, p.934-952;

MARIÁTEGUI, José Carlos. “¿Existe un pensamiento hispanoamericano?”. In.: Latinoamerica: Cuadernos de cultura latinoamericana, n. 34, México: UNAM, 1979. Originalmente publicado en Mundial, Lima, lo de mayo de 1925. Reproducido en El Argentino, La Plata, I4 de junio de 1925. Disponível em: 
http://ru.ffyl.unam.mx/bitstream/handle/I039I/2978/34_CCLat_1979_Mariategui.pdf?sequenc e=I\&isAllowed $=\mathrm{y}>$ Acesso em: 18 jan. 2019, I6h25;

MATOS, Maria Izilda. "História das mulheres e gênero: usos e perspectivas". In: PUGA, Vera Lúcia; MALUF, Sônia Weidner; PISCITELLI, Adriana; MELO, Hildete Pereira de. (Orgs.). Olhares feministas. Brasília: Ministério da Educação: Unesco, Coleção Educação Para Todos v. Io, 2009, p. 277-289;

MIGNOLO, Walter. "Desobediência epistêmica: a opção descolonial e o significado de identidade em política". In.: Cadernos de letras da UFF - Dossiê Literatura, língua e identidade. No 34, Niterói, 2008A, p.287-324;

. "Novas reflexões sobre a 'ideia da América Latina': a direita, a esquerda e a opção descolonial”. In.: Caderno CRH. V.2I, n53, Salvador, maio/ago. 2008B, p.239-252;

OLIVEIRA, Maria da Glória de. "A História disciplinada e seus "outros": reflexões sobre as (in)utilidades de uma categoria”. In: AVILA, Arthur de Lima, NICOLAZZI, Fernando e TURIN, Rodrigo (org.). A História (in)disciplinada: teoria, ensino e difusão do conhecimento histórico. [no prelo] I4p.;

PERROT, Michelle. "Escrever uma História das Mulheres: relato de uma experiência". In.: Revista Cadernos de Pagu, n. 4, p. 09-28, 1995;

QUIJANO, Aníbal. “Colonialidad del poder y clasificación social”. In.: Journal of world-systems research, v. II, n. 2, 2000, p. 342-386;

. "Colonialidade do poder: eurocentrismo e América Latina". In.: A colonialidade do saber: eurocentrismo e ciências sociais. Perspectivas latino-americanas. Buenos Aires: CLACSO, 2005, p.II7-I42. Disponível em: <http://bibliotecavirtual.clacso.org.ar/clacso/sursur/20100624103322/12_Quijano.pdf>;

RAGO Margareth. "Epistemologia feminista, gênero e história". In: PEDRO, Pedro, Joana; GROSSI, Miriam. (Orgs.) Masculino, feminino, plural. Florianópolis: Ed. Mulheres, 1998, p. OII7;

RÉMOND, René. Por uma história política. Rio de Janeiro: Editora FGV, 2003;

SCOTT, Joan. "História das mulheres". In: BURKE, Peter (Org.). A escrita da história: novas perspectivas. Trad. Magda Lopes. São Paulo: Edusp, 1992;

"Gênero: uma categoria útil de análise histórica". In.: Educação \& Realidade. Porto Alegre, v. 2O, n. 2, jul./dez. 1995; 
SEGATO, Rita Laura. "Gênero e colonialidade: em busca de chaves de leitura e de um vocabulário estratégico descolonial”. In.: e-cadernos ces [Online], I8, p.IO6-I3I, 20I2. Disponível em: <http://eces.revues.org/I533>;

SOIHET, Rachel; PEDRO, Joana Maria. “A emergência da pesquisa da História das Mulheres e das Relações de Gênero". In.: Revista Brasileira de História. São Paulo, v. 27, n. 54, p. 28I-300, 2007;

TILLY, Louise A. "Gênero, história das mulheres e história social”. In.: Revista Cadernos de Pagu. 1994, p. 29-62;

VASCONCELOS, José. "El pensamiento latinoamericano”. In.: Latinoamerica: cuadernos de cultura latinoamericana, n. 2I. México: UNAM, 1978. Originalmente publicado em: VASCONCELOS, José. Indología. Barcelona, I927. Disponível em: < http://ru.ffyl.unam.mx/bitstream/handle/IO39I/2965/2I_CCLat_I978_Vasconcelos.pdf?sequen ce=I\&isAllowed $=\mathrm{y}>$ Acesso em: 19 jan. 2019, Iohı.

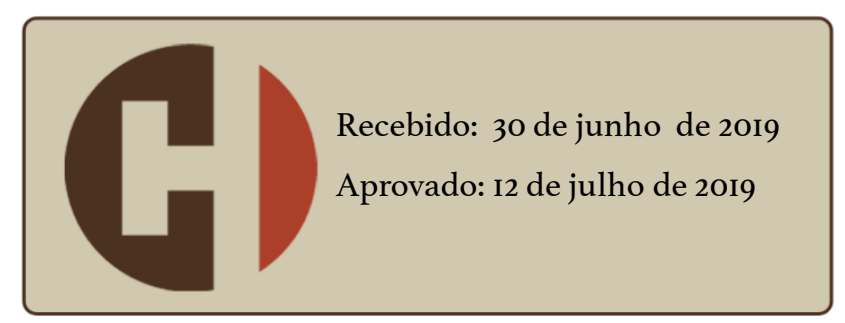

